\title{
OPERATOR MONOTONE FUNCTIONS INDUCED FROM LÖWNER-HEINZ INEQUALITY AND STRICTLY CHAOTIC ORDER
}

\author{
SAICHI IZUMINO AND NOBORU NAKAMURA
}

Abstract. Furuta presented direct and simplified proofs of operator monotonicity of functions

$$
\varphi(t)=\frac{t-1}{\log t} \quad \text { and } \quad \psi(t)=\frac{t \log t-t+1}{(\log t)^{2}}
$$

by using Löwner-Heinz inequality. Extending his method, we give a sequence of operator monotone functions $\left\{f_{k}(t)\right\}_{k=0}^{\infty}$ with $f_{0}(t)=\varphi(t)$ and $f_{1}(t)=\psi(t)$. We also study relations between $f_{k}(t)$ and strictly chaotic order defined among positive invertible operators and obtain some extensions of results due to Furuta.

Mathematics subject classification (2000): 47A63. functions

Key words and phrases: positive operators, chaotic order, Löwner-Heinz inequality, operator monotone

\section{REFERENCES}

[1] N. N. CHAN and M. K. KWONG, Hermitian matrix inequalities and a conjecture, Amer. Monthly 92 (1985), 533-541.

[2] M. FUJII, J. F. JIANG and E. KAMEI, Characterization of chaotic order and its application to Furuta inequality, Proc. Amer. Math. Soc. 125 (1997), 3655-3658.

[3] M. FUJII, J. F. JIANG and E. KAMEI, Characterization of chaotic order and its application to Furuta's type operator inequalities, Linear Multilinear Alg. 43 (1998), 339-349.

[4] M. FUJII, J. F. JIANG, E. KAMEI and K. TANAHASHI, A characterization of chaotic order and a problem, J. of Inequal. and Appl. 2 (1998), 149-156.

[5] T. FURUTA, Logarithmic order and dual logarithmic order, Operator Theory: Advances and Applications, Vol. 127, 279-290, Birkhäuser Verlag, Basel, 2001.

[6] T. FURUTA, An operator monotone function $\frac{t \log t-t+1}{\log ^{2} t}$ and strictly chaotic order, Linear Alg. and Its Appl. 341 (2002), 101-109.

[7] T. FuRUTA, Invitation to Linear Operators: From Matrices to Bounded Linear Operators on a Hilbert Space, Taylor and Francis, London and New York, 2001.

[8] E. HeINZ, Beiträge zur Störungstheorie der Spektralzerlegung, Math. Ann. 123 (1951), 415-438.

[9] F. HiAI and K. YANAGI, Hilbert Space and Linear Operators, Makinoshoten, 1995 (in Japanese).

[10] F. KuBO and T. ANDO, Means of positive linear operators, Math. Ann. 246 (1980), 205-224.

[11] M. K. Kwong, Some results on matrix monotone functions, Linear Alg. and Its Appl. 118 (1989), $129-153$

[12] K. LÖWNER, Über monotone Matrixfunktionen, Math. Z. 38 (1934), 177-216. 